
outcomes

\title{
Robot-assisted radical prostatectomy vs laparoscopic and open retropubic radical prostatectomy: functional outcomes 18 months after diagnosis from a national cohort study in England
}

\begin{abstract}
Julie Nossiter ${ }^{\star}, 1,2$, Arunan Sujenthiran ${ }^{2}$, Susan C Charman ${ }^{1,2}$, Paul J Cathcart ${ }^{3}$, Ajay Aggarwal ${ }^{1,2}$, Heather Payne ${ }^{4}$, Noel W Clarke ${ }^{5,6}$ and Jan van der Meulen ${ }^{1,2}$

${ }^{1}$ Department of Health Services Research \& Policy, London School of Hygiene and Tropical Medicine, London WC1E 7HT, UK; ${ }^{2}$ Clinical Effectiveness Unit, Royal College of Surgeons of England, London WC2A 3PE, UK; ${ }^{3}$ Department of Urology, Guy's and St Thomas' NHS Foundation Trust, London SE1 9RT, UK; ${ }^{4}$ Department of Oncology, University College London Hospitals NHS Foundation Trust, London NW1 2BU, UK; ${ }^{5}$ Department of Urology, The Christie, Manchester M20 4BX, UK and ${ }^{6}$ Department of Urology, Salford Royal NHS Foundation Trusts, Manchester M6 8HD, UK
\end{abstract}

Background: Robot-assisted radical prostatectomy (RARP) has been rapidly adopted without robust evidence comparing its functional outcomes against laparoscopic radical prostatectomy (LRP) or open retropubic radical prostatectomy (ORP) approaches. This study compared patient-reported functional outcomes following RARP, LRP or ORP.

Methods: All men diagnosed with prostate cancer in England during April - October 2014 who underwent radical prostatectomy were identified from the National Prostate Cancer Audit and mailed a questionnaire 18 months after diagnosis. Group differences in patient-reported sexual, urinary, bowel and hormonal function (EPIC-26 domain scores) and generic health-related quality of life (HRQoL; EQ-5D-5L scores), with adjustment for patient and tumour characteristics, were estimated using linear regression.

Results: In all, 2219 men (77.0\%) responded; 1310 (59.0\%) had RARP, 487 (21.9\%) LRP and 422 (19.0\%) ORP. RARP was associated with slightly higher adjusted mean EPIC-26 sexual function scores compared with LRP (3. 5 point difference; 95\% Cl: 1.1-5.9, $P=0.004)$ or ORP (4.0 point difference; $95 \% \mathrm{Cl}: 1.5-6.5, P=0.002$ ), which did not meet the threshold for a minimal clinically important difference (10-12 points). There were no significant differences in other EPIC-26 domain scores or HRQoL.

Conclusions: It is unlikely that the rapid adoption of RARP in the English NHS has produced substantial improvements in functional outcomes for patients.

Radical prostatectomy (RP) is a primary treatment option for men with localised prostate cancer (PCa) (Anandadas et al, 2011; Eggener et al, 2011; Donovan et al, 2016). Robot-assisted radical prostatectomy (RARP) has been rapidly adopted despite the lack of evidence demonstrating superior oncological or functional outcomes compared with laparoscopic (LRP) or open retropubic radical prostatectomy (ORP).

Various studies have compared sexual and urinary function and health-related quality of life (HRQoL) according to RP type (Ficarra et al, 2012a, b; Yaxley et al, 2016; Herlemann et al, 2017). 
However, many of these studies recruited patients from a single surgeon, single institution, or from tertiary medical centres. One community-based and two population-based studies from the USA and one multi-centre study from Sweden compared functional outcomes (Barry et al, 2012; Haglind et al, 2015; O'Neil et al, 2016; Herlemann et al, 2017). However, one of these studies used a predominantly historical control group (patients enrolled in 19941995; O’Neil et al, 2016) and none used fully validated measures of urinary continence and erectile function (Barry et al, 2012; Haglind et al, 2015; O'Neil et al, 2016; Herlemann et al, 2017).

The National Prostate Cancer Audit (NPCA) collects the data prospectively on the diagnosis, management and outcomes of every newly diagnosed man with PCa from all providers of PCa services in the National Health Service (NHS) in England and Wales. The patient-reported outcomes collected by the NPCA provide important and unique evidence. First, it is a national study that includes a truly representative sample - all patients in all surgical centres in the English NHS are invited to participate. Second, it is the only population-based study that uses the same validated instruments throughout the study to capture outcomes for patients who had radical treatment. Third, all participating patients were diagnosed in 2014, providing contemporary results. We used this evidence to compare the functional outcomes after RARP, LRP or ORP reported by patients 18 months after diagnosis.

\section{MATERIALS AND METHODS}

Study design and participants. All patients diagnosed with $\mathrm{PCa}$ in England between 1 April 2014 and 30 September 2014 as recorded in the NPCA database and who subsequently underwent $\mathrm{RP}$ were eligible for inclusion (ICD-10 and OPCS-4). This database includes relevant data items from the English National Cancer Registration and Analysis Service (www.ncras.nhs.uk) and the data items specific to the NPCA (The National Prostate Cancer Audit, 2016a).

This study was exempt from NHS Research Ethics Committee approval because it involved analysis of pseudonymised linked data collected for the purpose of service evaluation as part of the National Clinical Audit and Patient Outcomes Programme.

Survey design, administration and data handling. The NPCA patient questionnaire was designed to determine patients' views of their functional outcomes and their HRQoL following radical treatment. The questionnaire includes the EPIC-26, a validated instrument comprising 26 items to measure patient function and bother in five domains (urinary incontinence; urinary irritation/ obstruction; bowel function; sexual function; hormonal disturbance). Each domain has 4-7 items. The validated summary score for each domain ranges from 0 to 100 with higher scores representing better function (Szymanski et al, 2010). Thresholds for a minimal clinically important difference (MCID) have been estimated for each EPIC-26 domain, representing changes considered to be meaningful for patients (Skolarus et al, 2015).

The EuroQol (EQ-5D-5L) describes generic HRQoL based on five domains (mobility, self-care, usual activities, pain/discomfort, and anxiety/depression) with responses at five levels ('no problems', 'slight problems', 'moderate problems', 'severe problems', and 'unable to/extreme problems'). An index score, expressed on a scale with 0 representing 'death' and 1 'perfect health', is calculated by matching the pattern of the five responses against a set of utilities derived from the general UK population (Herdman et al, 2011).

Questionnaires were mailed to the homes of all identified men 18 months after they were diagnosed. Two reminders were sent to non-responders 3 and 6 weeks after the first mail out.
The survey response data were linked to records from the NPCA prospective audit database and Hospital Episodes Statistics (HES), an administrative database of all admissions to the English NHS (http://content.digital.nhs.uk/hes). The ICD-10 system classifies diseases and other health conditions and the OPCS-4 classifies interventions and surgical procedures (ICD-10 and OPCS-4).

The survey questionnaire provided the data on ethnicity and comorbidities. The NPCA database was the data source for age at diagnosis, tumour characteristics according to TNM scores, Gleason biopsy score, serum PSA and asdditional treatments (adjuvant/salvage external beam radiotherapy and androgen deprivation therapy [ADT]). Hospital Episodes Statistics was used to determine socioeconomic deprivation and type of RP (OPCS-4 Classification of Diseases codes for RARP: Y753, Y765; ORP: Y508, Y751, Y752, Y763, Y768).

Socioeconomic deprivation was measured with the Index of Multiple Deprivation (IMD) for lower super output areas (small geographic areas with population of $\sim 1500$ people) (Noble et al, 2008). Areas were grouped into five categories according to national quintiles of the IMD ranking with higher scores indicating more deprivation.

Men were classified as having low-risk localised, intermediaterisk localised, locally advanced or advanced cancer based on their TNM stage, Gleason score, and PSA level, according to a previously developed algorithm (The National Prostate Cancer Audit, 2016b).

Outcomes. Primary outcome measures were the five EPIC-26 domain scores and the EQ-5D-5L index score according to RP technique. Missing patient response data to individual questions were handled in accordance with respective guidelines for EPIC-26 and EQ-5D-5L (The University of Michigan, 2002; The EuroQoL Group, 2015).

Statistical analysis. We used multivariable linear regression to estimate differences in outcomes with adjustment for patient characteristics, including age, patient-reported number of comorbidities and ethnicity, cancer risk group according to NPCA data (determined on the basis of TNM stage, Gleason score and PSA level), and socioeconomic status according to HES. All $P$-values were based on the Wald test.

Multiple imputation by chained equations accounted for missing values of the adjustment variables and outcomes so that regression models included all 2219 patients (White et al, 2011). Missing values were replaced with 50 sets of plausible values and Rubin's rules were used to combine estimates and obtain adjusted differences with $95 \%$ confidence intervals (95\% CI).

All reported $P$-values are two-sided and $P<0.05$ was considered statistically significant without adjustment for multiple comparisons. Adjusted differences in EPIC-26 domain scores were considered to be clinically relevant if the differences reached the threshold for a MCID (Skolarus et al, 2015). The data analysis was undertaken using Stata version 14 (StataCorp. 2015. Stata Statistical Software (College Station, TX, USA).

\section{RESULTS}

Response rate and data completeness. Of the 2883 eligible men who underwent RP at all prostatectomy centres $(n=55)$ in England and received a questionnaire, 2219 (77.0\%) responded. Compared with non-responders, responders tended to be older, were more commonly of white ethnicity, reported fewer comorbidities, and were less likely to live in more socioeconomically deprived areas (Supplementary Table 1). The missing data levels were low, typically $<5 \%$ for the majority of fields in the questionnaire. 
Patient characteristics. Of the 2219 responders, 1310 (59.0\%) had RARP, 487 (21.9\%) LRP, and 422 (19.0\%) ORP. Most responders, 1954 men (91.4\%), underwent surgery within 6 months from diagnosis and 1714 men (80.1\%) completed the surveys $12-18$ months from surgery. There was no evidence that timing of surgery was related to RP type.

Patient characteristics are presented in Table 1 . The majority of men were $\leqslant 70$ years $(89.2 \%)$ and of white ethnicity $(93.9 \%)$. Overall, men from more socio-economically deprived backgrounds were under-represented. About one-third of men reported no comorbidities. In all, $7.6 \%$ of men also received radiotherapy and $4.6 \%$ ADT. There were only small differences in patient characteristics across RP group. For example, men who underwent ORP tended to be slightly older, and more often of white ethnicity. Men who underwent LRP were less likely to be in the most socioeconomically deprived national quintile.

Tumour characteristics. Tumour characteristics were very similar across surgical groups (Table 2). Overall, 59.6\% of men had tumour stage T2 and $38.2 \%$ stage T3/T4. However, men having ORP slightly more often had positive nodal stage N1, a Gleason score $\geqslant 8$, and PSA levels $\geqslant 10$. Consequently, the cancer risk profiles for men undergoing RARP or LRP were similar, but slightly more men undergoing ORP had locally advanced or advanced disease.

Patient-reported outcomes according to RP type. Robot-assisted radical prostatectomy was associated with slightly higher adjusted mean EPIC-26 sexual function scores (Table 3) compared with LRP (adjusted mean difference 3.5 points; 95\% CI: 1.1-5.9, $P=0.004$ ) or ORP (adjusted mean difference $4 \cdot 0$ points; $95 \%$ CI: 1.5-6.5, $P=0.002)$. These differences were smaller than the

Table 1. Patient characteristics by type of radical prostatectomy

\begin{tabular}{|c|c|c|c|c|}
\hline & RARP $n(\%)$ & LRP $n(\%)$ & ORP $n(\%)$ & Total $n(\%)$ \\
\hline No. of patients & 1310 (59.0\%) & 487 (21.9\%) & 422 (19.0\%) & 2,219 \\
\hline \multicolumn{5}{|l|}{$\begin{array}{l}\text { Age at diagnosis } \\
\text { (years) }\end{array}$} \\
\hline$\leqslant 60$ & $368(29.2 \%)$ & $121(25.9 \%)$ & $88(22.0 \%)$ & 577 (27.1\%) \\
\hline $61-70$ & 780 (61.9\%) & $284(60.7 \%)$ & $256(63.8 \%)$ & 1320 (62.1\%) \\
\hline$>70$ & 111 (8.8\%) & 62 (13.2\%) & 57 (14.2\%) & 230 (10.8\%) \\
\hline Missing & 51 & 20 & 21 & 92 \\
\hline \multicolumn{5}{|l|}{ Ethnicity } \\
\hline White & $1180(92.5 \%)$ & $453(94.0 \%)$ & $399(97.6 \%)$ & 2,032 (93.9\%) \\
\hline Non-white & 94 (7.8\%) & $28(5.8 \%)$ & 10 (2.4\%) & 132 (6.1\%) \\
\hline Missing & 36 & 6 & 13 & 55 \\
\hline \multicolumn{5}{|l|}{$\begin{array}{l}\text { Socioeconomic } \\
\text { deprivation }\end{array}$} \\
\hline $\begin{array}{l}\text { Least deprived } \\
\text { quintile }\end{array}$ & $339(26.3 \%)$ & $131(27.0 \%)$ & $119(28.2 \%)$ & 589 (26.8\%) \\
\hline 2nd & 311 (24.1\%) & $122(25.2 \%)$ & 99 (23.5\%) & 532 (24.2\%) \\
\hline $3 r d$ & 292 (22.\%) & $117(24.3 \%)$ & 87 (20.6\%) & 496 (22.6\%) \\
\hline 4th & $186(14.5 \%)$ & $78(16.1 \%)$ & 57 (13.5\%) & 321 (14.7\%) \\
\hline $\begin{array}{l}\text { Most deprived } \\
\text { quintile }\end{array}$ & 161 (12.5\%) & $36(7.4 \%)$ & $60(14.2 \%)$ & 257 (11.7\%) \\
\hline Missing & 21 & 3 & 0 & 24 \\
\hline \multicolumn{5}{|l|}{ Comorbidities } \\
\hline 0 & 465 (35.5\%) & 149 (30.7\%) & $136(32.2 \%)$ & 750 (33.8\%) \\
\hline$\geqslant 1$ & $845(64.5 \%)$ & $338(69.3 \%)$ & $286(67.8 \%)$ & 1469 (66.2\%) \\
\hline \multicolumn{5}{|l|}{$\begin{array}{l}\text { Additional } \\
\text { treatments }\end{array}$} \\
\hline $\begin{array}{l}\text { Radiotherapy } \\
\text { (EBRT) }\end{array}$ & $97(7.4 \%)$ & $35(7.2 \%)$ & $38(9.0 \%)$ & $170(7.6 \%)$ \\
\hline $\begin{array}{l}\text { Androgen } \\
\text { deprivation }\end{array}$ & 51 (3.9\%) & 22 (4.5\%) & $28(2.8 \%)$ & 101 (4.6\%) \\
\hline
\end{tabular}

established threshold for a MCID of 10-12 points (Skolarus et al, 2015).

There was no significant difference in EPIC-26 urinary incontinence, urinary irritation, bowel and hormonal function scores or EQ5D-5L index scores between RARP and LRP or ORP (Table 3).

\section{DISCUSSION}

In this contemporary, observational study of all men diagnosed with PCa in the English NHS between 01 April 2014 and 31 October 2014 who underwent RP in prostatectomy centres nationwide, RARP was associated with better sexual function than LRP or ORP, 18 months after diagnosis. However, the difference in EPIC-26 sexual function scores (3.5 point difference for RARP compared with LRP and 4 point difference for RARP compared with ORP on a scale ranging from 0 to 100) is considerably smaller than the established threshold for a clinically meaningful change (10-12 points) (Skolarus et al, 2015). This suggests that most patients would not identify this difference in sexual function as important. There was no significant difference in other measured functional parameters, including continence or HRQoL.

Our results concur with a recent phase 3 randomised controlled trial (RCT) comparing 163 men undergoing RARP with 163 men having ORP (Yaxley et al, 2016). This, to our knowledge, the largest RCT to date, found no significant differences in the EPIC sexual and urinary function scores 12 weeks after surgery. However, this RCT included a young cohort of patients (mean

\begin{tabular}{|c|c|c|c|c|}
\hline & RARP $n(\%)$ & LRP $n(\%)$ & ORP $n(\%)$ & Total $n(\%)$ \\
\hline No. of patients & 1310 (59.0\%) & 487 (21.9\%) & $422(19.0 \%)$ & 2219 \\
\hline \multicolumn{5}{|l|}{ Tumour stage } \\
\hline $\begin{array}{l}\text { T stage } \\
\text { T1 } \\
\text { T2 } \\
\text { T3/T4 } \\
\text { Missing }\end{array}$ & $\begin{array}{c}28(2.4 \%) \\
713(60.3 \%) \\
441(37.2 \%) \\
128\end{array}$ & $\begin{array}{c}10(2.3 \%) \\
256(58.5 \%) \\
173(39.3 \%) \\
48\end{array}$ & $\begin{array}{c}8(2.0 \%) \\
236(58.7 \%) \\
158(39 \%) \\
20\end{array}$ & $\begin{array}{c}46(2.3 \%) \\
1205(59.6 \%) \\
772(38.2 \%) \\
196\end{array}$ \\
\hline $\begin{array}{l}\text { N stage } \\
\text { N0 } \\
\text { N1 } \\
\text { Missing }\end{array}$ & $\begin{array}{c}1057(96.7 \%) \\
36(3.3 \%) \\
217\end{array}$ & $\begin{array}{c}389(98.2 \%) \\
7(1.8 \%) \\
91\end{array}$ & $\begin{array}{c}370(94.9 \%) \\
19(4.9 \%) \\
33\end{array}$ & $\begin{array}{c}1816(96.5 \%) \\
62(3.3 \%) \\
341\end{array}$ \\
\hline $\begin{array}{l}\text { Gleason score } \\
\quad \leqslant 6 \\
7 \\
\geqslant 8 \\
\text { Missing }\end{array}$ & $\begin{array}{c}217(20.6 \%) \\
708(67.2 \%) \\
129(12.2 \%) \\
256\end{array}$ & $\begin{array}{c}108(24.9 \%) \\
283(65.3 \%) \\
43(9.9 \%) \\
53\end{array}$ & $\begin{array}{c}68(19.0 \%) \\
224(62.6 \%) \\
66(18.4 \%) \\
64\end{array}$ & $\begin{array}{c}393(21.3 \%) \\
1215(65.8 \%) \\
238(12.9 \%) \\
373\end{array}$ \\
\hline $\begin{array}{l}\text { PSA }\left(\mathrm{ng} / \mathrm{ml}^{-1}\right) \\
\quad<10 \\
10-20 \\
>20 \\
\text { Missing }\end{array}$ & $\begin{array}{c}664(66.9 \%) \\
264(26.6 \%) \\
65(6.6 \%) \\
317\end{array}$ & $\begin{array}{c}296(72.4 \%) \\
97(23.7 \%) \\
16(3.9 \%) \\
78\end{array}$ & $\begin{array}{c}212(60.1 \%) \\
115(32.6 \%) \\
26(7.4 \%) \\
69\end{array}$ & $\begin{array}{c}1172(66.8 \%) \\
476(27.1 \%) \\
107(6.1 \%) \\
464\end{array}$ \\
\hline $\begin{array}{l}\text { Cancer risk profile } \\
\text { Low/ } \\
\text { intermediate } \\
\text { Locally } \\
\text { advanced/ } \\
\text { advanced } \\
\text { Insufficient } \\
\text { information }{ }^{c}\end{array}$ & $\begin{array}{l}547(50.8 \%) \\
530(49.2 \%)\end{array}$ & $\begin{array}{l}220(51.9 \%) \\
204(48.1 \%)\end{array}$ & $\begin{array}{l}172(45.7 \%) \\
204(54.3 \%)\end{array}$ & $\begin{array}{l}939(50.0 \%) \\
938(50.0 \%)\end{array}$ \\
\hline \multicolumn{5}{|c|}{ 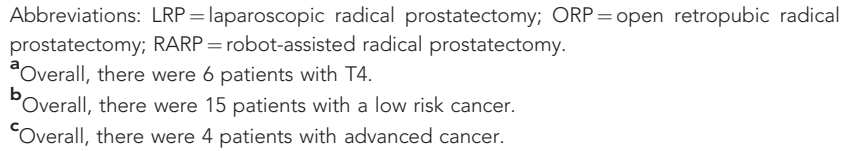 } \\
\hline
\end{tabular}


Table 3. Relationship between patient-reported outcomes post-procedure and type of radical prostatectomy (ORP, LRP and RALP): overall domain scores for EPIC-26 and EQ5D-5L and adjusted differences for RARP vs LRP and RARP vs ORP

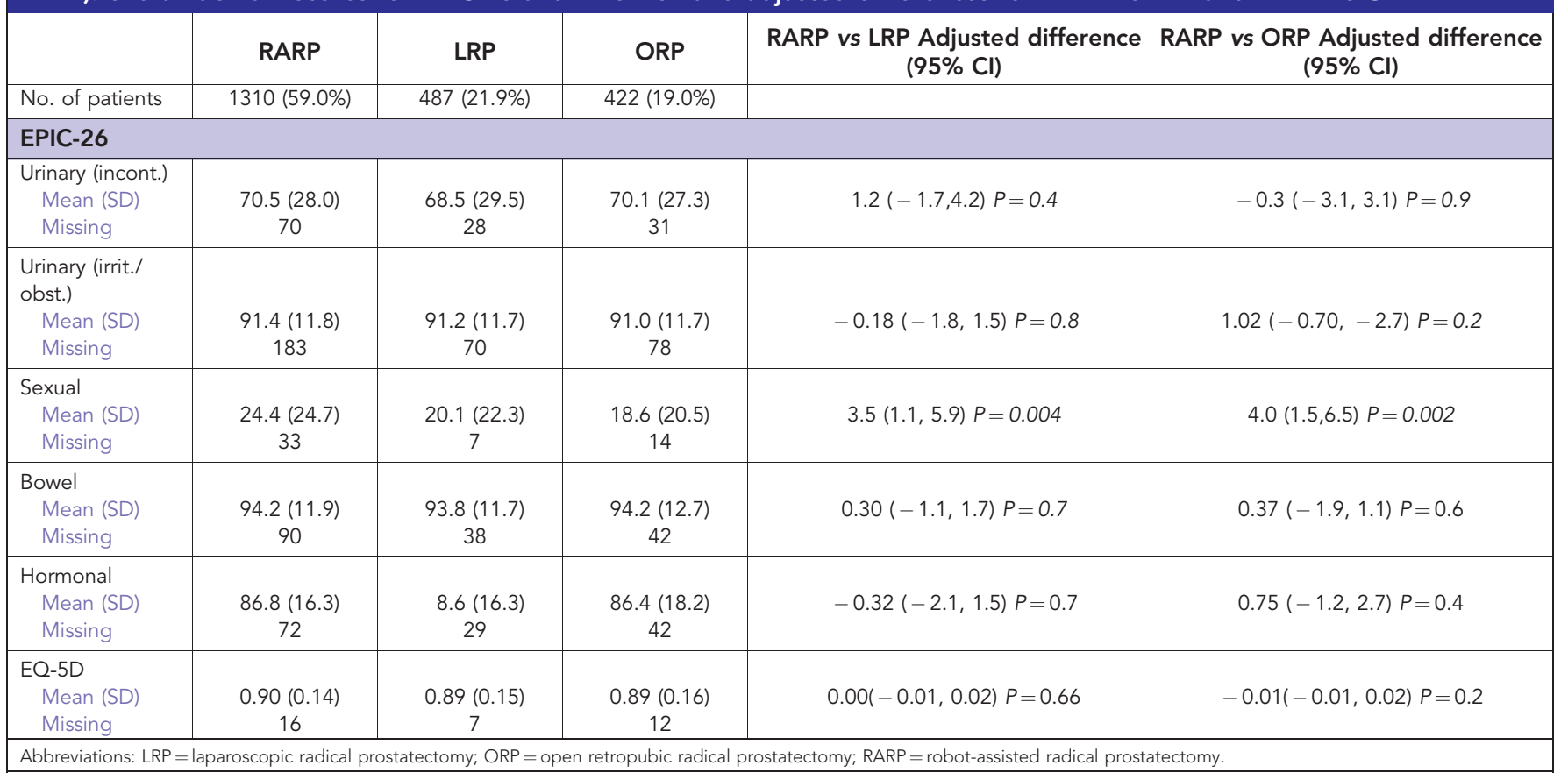

age, 60 years), compared two high-volume surgeons and used the EPIC-50 instrument rather than the EPIC-26, and these differences in study design are likely to explain the lower sexual function scores reported in our observational study. Previous smaller RCTs reported that patients having RARP had significantly better sexual function one year after surgery (Asimakopoulos et al, 2011) and had improved recovery of both urinary and sexual function (Porpiglia et al, 2013). This is in agreement with the results of previous systematic reviews comparing RARP with other RP types, including studies with a range of different designs (Ficarra et al, 2012a).

Other population-based or multi-centre studies demonstrated no or at best modest improvements in functional outcomes with RARP. However, these studies are limited by the use of nonstandard instruments or single items to capture sexual or urinary function and inclusion of selected populations (Barry et al, 2012; Haglind et al, 2015; Gershman et al, 2016; O’Neil et al, 2016; Herlemann et al, 2017).

Three studies in the USA compared RARP and ORP. The first of these studies included patients from a claims-based database and found that patients reported a moderate or big problem with urinary continence following RARP but there was no difference in sexual function (Barry et al, 2012). The second study compared men having RARP in 2011 and 2012, with a historical comparison group who underwent ORP predominantly in 1994 and 1995, and found no significant difference in 12-month urinary function and a modest increase in sexual function with RARP (O'Neil et al, 2016). The third study included men who had a RP around 2011 and demonstrated higher, unadjusted 12-month urinary incontinence scores for RARP with no difference in functioning after this time (Herlemann et al, 2017).

A study comparing patients having RARP, LRP, and ORP performed by high-volume surgeons ( $>25$ procedures per year) in two centres in the USA found no evidence that sexual or urinary functional outcomes were linked to type of surgery (Gershman et al, 2016). It is important to note that European, populationbased studies are lacking. One study in Sweden including 14 centres found slightly better 12 -month sexual function in patients having RARP compared with ORP but little difference in urinary function (Haglind et al, 2015).

A strength of our study is that it reports results from a contemporary national cohort study that collected data prospectively on all men newly diagnosed with PCa in the English NHS in 2014. Further strengths include a robust sample size, a high response rate to the survey $(77.0 \%)$, the collection of patient reported functional outcomes at a fixed time period after diagnosis, and the use of the same validated instruments to determine disease-specific function and HRQoL from all patients.

Our study is subject to confounding by clinical indication. However, the observed patient and tumour characteristics were very similar across prostatectomy type, which reduces the potential impact of confounding. There were small differences that may have a favourable impact on patients who had RARP, given that these men were slightly younger with less comorbidities. Conversely, patients who underwent ORP more often had locally advance/ advanced disease (nodal positivity, a Gleason score $\geqslant 8$, or PSA level of $\geqslant 10$ ), which may have a less favourable impact on these patients. We adjusted for age, comorbidity, ethnicity, socioeconomic background, and cancer risk profile in the analyses, but these characteristics had very little impact on the difference between the RP groups. Furthermore, the choice of type of surgery depended strongly on where a patient had his treatment rather than on his specific characteristics because most hospitals offer only one surgical technique at a given time (NPCA unpublished data). This further reduces the likelihood of patients being allocated to one treatment or another based on their individual risk characteristics at diagnosis. Data on lymph node dissection were unavailable in this study.

Similar to previous studies undertaken in England that presented patient-reported outcomes, non-responders were younger, more often non-white, and lived in less affluent areas (Hutchings et al, 2012). However, the response rate did not vary according to type of prostatectomy, suggesting that the impact of non-response on the observed difference is likely to be very small. As men were surveyed 18 months after diagnosis, the time from surgery to completion varied. However, the majority of men 
completed the survey $12-18$ months after surgery and there was no evidence that timing of surgery was related to RP type.

We were unable to administer the questionnaire at the time of diagnosis, making it impossible to adjust for potential baseline differences in patient function, bother and generic HRQoL. However, we included one question in our 18-month questionnaire asking men 'How would you rate your ability to have an erection at the time of diagnosis?'. The proportion of men who indicated that this was 'very poor/none' did not vary according to the type of prostatectomy (reported by $19.4 \%$ of men who underwent RARP, $20.3 \%$ who had LRP, and $20.7 \%$ who had ORP), which further supports the validity of our comparison.

Finally, this study was carried out at a time when RARP use was growing rapidly in the English NHS. In 2010, 12 of the 65 prostatectomy centres (19\%) provided RARP, but by 2017, this had changed to 42 of the remaining 49 centres (86\%) (Aggarwal et al, 2017). A 'learning curve' may therefore have had an impact on the results. The ongoing collection of patient-reported outcomes after radical treatment for $\mathrm{PCa}$ in the NHS will potentially demonstrate to what extent outcomes with RARP will further improve.

Robot-assisted radical prostatectomy has been rapidly adopted in many countries and has become the most common type of RP within the English NHS (The National Prostate Cancer Audit, 2016b; Aggarwal et al, 2017; Sujenthiran et al, 2017). Its use was partly informed by a large economic evaluation that found that RARP had a lower rate of positive surgical margins (18\%) than LRP (24\%), in addition to lower blood loss and shorter length of hospital stay although no differences in functional outcomes were reported (Ramsay et al, 2012). The first phase 3 RCT comparing RARP and ORP reported no difference in surgical margin status (Yaxley et al, 2016).

The results of our study, with its lack of clinically relevant differences in functional outcomes and in generic HRQoL among patients who had RARP, LRP, or ORP, do not support the dramatic shift to RARP, which has taken place in the English NHS and worldwide. These findings have wider implications for the English NHS when considering the adoption of new technology. Patient reported outcome measures provide important information enabling the comparison of treatments and providers, and support decision making by patients.

\section{CONCLUSIONS}

While RARP was associated with marginally better sexual function scores than LRP or ORP as reported by men 18 months after diagnosis, this difference is small and unlikely to be clinically significant. Our study includes a representative sample, as all men who had a RP in 2014 in each of the surgical centres in the English NHS were invited to participate. Our results demonstrate that the rapid adoption of RARP in the English NHS is unlikely to lead to substantial improvements in functional outcomes for patients. Continued monitoring of patient-reported outcomes is required to explore if the benefits of RARP will emerge in the future after urologists have gained further experience with this type of surgery. The expertise and skill of an individual surgeon, and comparative performance of a surgical centre should drive treatment decisions. Rather than surgical modality alone, robust provider-level functional outcome measures are needed to support decision making by patients.

\section{ACKNOWLEDGEMENTS}

We thank all men who returned the survey questionnaires and NHS staff for their support of collecting the clinical data, the National Cancer Registration and Analysis Service (www.ncras.nhs.uk), which is part of Public Health England, for providing cancer registry data, and Quality Health (www.qualityhealth.co.uk) for administering the survey. Hospital Episode Statistics were made available by NHS Digital (www.digital.nhs.uk); re-used with the permission of NHS Digital; all rights reserved. This work was funded by the Healthcare Quality Improvement Partnership on behalf of NHS England and the Welsh Government.

\section{CONFLICT OF INTEREST}

The authors declare no conflict of interest.

\section{DISCLAIMER}

The funders of the study had no role in the study design, data collection, data analysis, data interpretation, or writing of the report.

\section{REFERENCES}

Aggarwal A, Lewis D, Mason M, Purushotham A, Sullivan R, Van der Meulen JH (2017) Effect of patient choice and hospital competition on service configuration and technology adoption within cancer surgery: a national, population-based study. Lancet Oncol 18(11): 1445-1453.

Anandadas CN, Davidson SE, Clarke NW, Brown SC, Logue JP, Gilmore L, Swindell R, Collins GN, O’Reilly PH, Wemyss-Holden GD, Lau MW (2011) Quality of Life in men treated for early prostate cancer: A prospective patient preference cohort study. J Cancer Ther 2(4): 448-457.

Asimakopoulos AD, Pereira Fraga CT, Annino F, Pasqualetti P, Calado AA, Mugnier C (2011) Randomized comparison between laparoscopic and robotassisted nerve-sparing radical prostatectomy. J Sex Med 8(5): 1503-1512.

Barry MJ, Gallagher PM, Skinner JS, Fowler FJ (2012) Adverse effects of robotic-assisted laparoscopic versus open retropubic radical prostatectomy among a nationwide random sample of medicare-age men. J Clin Oncol 30(5): $513-518$.

Donovan JL, Hamdy FC, Lane JA, Mason M, Metcalfe C, Walsh E, Blazeby JM, Peters TJ, Holding P, Bonnington S, Lennon T (2016) Patient-reported outcomes after monitoring, surgery, or radiotherapy for prostate cancer. $N$ Engl J Med 375(15): 1425-1437.

Eggener SE, Scardino PT, Walsh PC, Han M, Partin AW, Trock BJ, Feng Z, Wood DP, Eastham JA, Yossepowitch O, Rabah DM (2011) Predicting 15year prostate cancer specific mortality after radical prostatectomy. J Urol 185(3): 869-875.

Ficarra V, Novara G, Rosen RC, Artibani W, Carroll PR, Costello A, Menon M, Montorsi F, Patel VR, Stolzenburg JU, Van der Poel H (2012a) Systematic review and meta-analysis of studies reporting urinary continence recovery after robot-assisted radical prostatectomy. Eur Urol 62(3): 405-417.

Ficarra V, Novara G, Ahlering TE, Costello A, Eastham JA, Graefen M, Guazzoni G, Menon M, Mottrie A, Patel VR, Van der Poel H (2012b) Systematic review and meta-analysis of studies reporting potency rates after robot-assisted radical prostatectomy. Eur Urol 62(3): 418-430.

Gershman B, Psutka SP, McGovern FJ, Dahl DM, Tabatabaei S, Gettman MT, Frank I, Carlson RE, Rangel LJ, Barry MJ, Blute ML (2016) Patientreported functional outcomes following open, laparoscopic, and robotic assisted radical prostatectomy performed by high-volume surgeons at high-volume hospitals. Eur Urol Focus 2(2): 172-179.

Haglind E, Carlsson S, Stranne J, Wallerstedt A, Wilderäng U, Thorsteinsdottir T, Lagerkvist M, Damber JE, Bjartell A, Hugosson J, Wiklund P (2015) Urinary incontinence and erectile dysfunction after robotic versus open radical prostatectomy: a prospective, controlled, nonrandomised trial. Eur Urol 68(2): 216-225.

Herdman M, Gudex C, Lloyd A, Janssen M, Kind P, Parkin D, Bonsel G, Badia X (2011) Development and preliminary testing of the new five-level version of EQ-5D (EQ-5D-5L). Qual Life Res 20(10): 1727-1736.

Herlemann A, Cowan JE, Carroll PR, Cooperber MR (2017) Communitybased outcomes of open versus robot-assisted radical prostatectomy. Eur 
Urol. e-pub ahead of print 03 October 2017; doi:10.1016/ j.eururo.2017.04.027.

Hospital Episodes Statistics. Available from http://content.digital.nhs.uk/ hesaccessed Dec 14, 2016.

Hutchings A, Neuburger J, Frie KG, Black N, van der Meulen J (2012) Factors associated with non-response in routine use of patient reported outcome measures after elective surgery in England. Health Qual Life Outcomes 10(1): 34.

ICD-10 and OPCS-4. ICD-10 International Classification of Diseases and OPCS-4 Classification of Interventions and Procedures. Available at: https://digital.nhs.uk/article/1117/Clinical-Classifications. (accessed 14 December 2016).

Noble M, Wilkinson K, Whitworth A, Dibben C, Barnes H (2008) The English Indices of Deprivation 2007. HMSO: London.

O’Neil B, Koyama T, Alvarez J, Conwill RM, Albertsen PC, Cooperberg MR, Goodman M, Greenfield S, Hamilton AS, Hoffman KE, Hoffman RM (2016) The comparative harms of open and robotic prostatectomy in population based samples. J Urol 195(2): 321-329.

Porpiglia F, Morra I, Chiarissi ML, Manfredi M, Mele F, Grande S, Ragni F, Poggio M, Fiori C (2013) Randomised controlled trial comparing laparoscopic and robot-assisted radical prostatectomy. Eur Urol 63(4): 606-614.

Ramsay C, Pickard R, Robertson C, Close A, Vale L, Armstrong N, Barocas DA, Eden CG, Fraser C, Gurung T, Jenkinson D (2012) Systematic review and economic modelling of the relative clinical benefit and cost-effectiveness of laparoscopic surgery and robotic surgery for removal of the prostate in men with localised prostate cancer. Health Technol Assess 16(41): 1-313.

Skolarus TA, Dunn RL, Sanda MG, Chang P, Greenfield TK, Litwin MS, Wei JT, PROSTQA Consortium (2015) Minimally important difference for the expanded prostate cancer index composite short form. Urology 85(1): 101-106.

Sujenthiran A, Charman SC, Parry M, Nossiter J, Aggarwal A, Dasgupta P, Payne H, Clarke NW, Cathcart P, van der Meulen J (2017) Quantifying urinary complications after radical prostatectomy: the development and validation of a surgical performance indicator using hospital administrative data. BJU Int 120(2): 219-225.

Szymanski KM, Wei JT, Dunn RL, Sanda MG (2010) Development and validation of an abbreviated version of the expanded prostate cancer index composite instrument for measuring health-related quality of life among prostate cancer survivors. Urology 76(5): 1245-1250.

The EuroQol Group (2015) EQ-5D-5L User Guide. Basic information on how to use the EQ-5D-5L instrument. Available at: http://www.euroqol.org/ fileadmin/user_upload/Documenten/PDF/Folders_Flyers/EQ-5D5L_UserGuide_2015.pdf. (accessed 14 .December 2016).

The National Prostate Cancer Audit (2016a) Prospective audit minimum dataset. Version 2.1. Available at: https://www.npca.org.uk/content/ uploads/2017/01/NPCA_MDS-V2.1_-17_01_16.pdf. (accessed 14 December 2016).

The National Prostate Cancer Audit (2016b) Third Year Annual Report Results of the NPCA prospective audit and patient survey. The Royal Collge of Surgeons of England: London, Available at: https://www.npca.org.uk/ content/uploads/2016/12/NPCA-2016-Annual-Report-Final.pdfaccessed 14 December 2016.

The University of Michigan (2002) Scoring Instructions for the Expanded Prostate cancer Index Composite Short Form (EPIC-26). Available at: $\overline{\mathrm{h}}$ ttps://medicine.umich.edu/sites/default/files/content/downloads/ Scoring\%20Instructions\%20for\%20the\%20EPIC\%2026.pdf. (accessed 14 December 2016).

White IR, Royston P, Wood AM (2011) Multiple imputation using chained equations: issues and guidance for practice. Stat Med 30(4): 377-399.

Yaxley JW, Coughlin GD, Chambers SK, Occhipinti S, Samaratunga H, Zajdlewicz L, Dunglison N, Carter R, Williams S, Payton DJ, Perry-Keene J (2016) Robot-assisted laparoscopic prostatectomy versus open radical retropubic prostatectomy: early outcomes from a randomised controlled phase 3 study. Lancet 388(10049): 1057-1066.

(c) (1)(2) This work is licensed under the Creative Commons (c) ${ }_{\text {BY NG SA }}$ Attribution-Non-Commercial-Share Alike 4.0 International License. To view a copy of this license, visit http:// creativecommons.org/licenses/by-nc-sa/4.0/

(C) The Author(s) named above 2018

Supplementary Information accompanies this paper on British Journal of Cancer website (http://www.nature.com/bjc) 